\title{
Strong Convergence to Common Fixed Points for Countable Families of Asymptotically Nonexpansive Mappings and Semigroups
}

\author{
Kriengsak Wattanawitoon ${ }^{1,2}$ and Poom Kumam ${ }^{2,3}$ \\ ${ }^{1}$ Department of Mathematics and Statistics, Faculty of Science and Agricultural Technology, \\ Rajamangala University of Technology Lanna Tak, Tak 63000, Thailand \\ ${ }^{2}$ Centre of Excellence in Mathematics, CHE, Si Ayuthaya Road, Bangkok 10400, Thailand \\ ${ }^{3}$ Department of Mathematics, Faculty of Science, King Mongkut's University of Technology Thonburi \\ (KMUTT), Bangmod, Thrungkru, Bangkok 10140, Thailand
}

Correspondence should be addressed to Poom Kumam, poom.kum@kmutt.ac.th

Received 15 April 2010; Accepted 11 October 2010

Academic Editor: A. T. M. Lau

Copyright (c) 2010 K. Wattanawitoon and P. Kumam. This is an open access article distributed under the Creative Commons Attribution License, which permits unrestricted use, distribution, and reproduction in any medium, provided the original work is properly cited.

We prove strong convergence theorems for countable families of asymptotically nonexpansive mappings and semigroups in Hilbert spaces. Our results extend and improve the recent results of Nakajo and Takahashi (2003) and of Zegeye and Shahzad (2008) from the class of nonexpansive mappings to asymptotically nonexpansive mappings.

\section{Introduction}

Throughout this paper, Let $H$ be a real Hilbert space with inner product $\langle\cdot, \cdot\rangle$ and norm $\|\cdot\|$, and we write $x_{n} \rightarrow x$ to indicate that the sequence $\left\{x_{n}\right\}$ converges strongly to $x$. Let $C$ be a nonempty closed convex subset of $H$, and let $T: C \rightarrow C$ be a mapping. Recall that $T$ is nonexpansive if $\|T x-T y\| \leq\|x-y\|$, for all $x, y \in C$. We denote the set of fixed points of $T$ by $F(T)$, that is, $F(T)=\{x \in C: x=T x\}$. A mapping $T$ is said to be asymptotically nonexpansive if there exists a sequence $\left\{k_{n}\right\}$ with $k_{n} \geq 1$ for all $n, \lim _{n \rightarrow \infty} k_{n}=1$, and

$$
\left\|T^{n} x-T^{n} y\right\| \leq k_{n}\|x-y\| \quad \forall n \geq 1, x, y \in C .
$$

Mann's iterative algorithm was introduced by Mann [1] in 1953. This iteration process is now known as Mann's iteration process, which is defined as

$$
x_{n+1}=\alpha_{n} x_{n}+\left(1-\alpha_{n}\right) T x_{n}, \quad n \geq 0,
$$


where the initial guess $x_{0}$ is taken in $C$ arbitrarily and the sequence $\left\{\alpha_{n}\right\}_{n=0}^{\infty}$ is in the interval $[0,1]$.

In 1967, Halpern [2] first introduced the following iteration scheme:

$$
x_{n+1}=\alpha_{n} u+\left(1-\alpha_{n}\right) T x_{n}
$$

for all $n \in \mathbb{N}$, where $x_{1}=x \in C$ and $\left\{\alpha_{n}\right\}$ is a sequence in $[0,1]$. This iteration process is called a Halpern-type iteration.

Recall also that a one-parameter family $\tau=\{T(t): 0 \leq t<\infty\}$ of self-mappings of a nonempty closed convex subset $C$ of a Hilbert space $H$ is said to be a (continuous) Lipschitzian semigroup on $C$ if the following conditions are satisfied:

(a) $T(0) x=x, x \in C$;

(b) $T(t+s) x=T(t) T(s) x$, for all $t, s \geq 0, x \in C$;

(c) for each $x \in C$, the map $t \mapsto T(t) x$ is continuous on $[0, \infty)$;

(d) there exists a bounded measurable function $L:(0, \infty) \rightarrow[0, \infty)$ such that, for each $t>0,\|T(t) x-T(t) y\| \leq L_{t}\|x-y\|$, for all $x, y \in C$.

A Lipschitzian semigroup $\tau$ is called nonexpansive if $L_{t}=1$ for all $t>0$, and asymptotically nonexpansive if $\limsup _{t \rightarrow \infty} L_{t} \leq 1$. We denote by $F(\tau)$ the set of fixed points of the semigroup $\tau$, that is, $F(\tau)=\{x \in C: T(s) x=x, \forall s>0\}$.

In 2003, Nakajo and Takahashi [3] proposed the following modification of the Mann iteration method for a nonexpansive mapping $T$ in a Hilbert space $H$ :

$$
\begin{gathered}
x_{0} \in C, \quad \text { chosen arbitrarily, } \\
y_{n}=\alpha_{n} x_{n}+\left(1-\alpha_{n}\right) T x_{n}, \\
C_{n}=\left\{v \in C:\left\|y_{n}-v\right\| \leq\left\|x_{n}-v\right\|\right\}, \\
Q_{n}=\left\{v \in C:\left\langle x_{n}-v, x_{n}-x_{0}\right\rangle \geq 0\right\}, \\
x_{n+1}=P_{C_{n} \cap Q_{n}}\left(x_{0}\right),
\end{gathered}
$$

where $P_{C}$ denotes the metric projection from $H$ onto a closed convex subset $C$ of $H$. They proved that the sequence $\left\{x_{n}\right\}$ converges weakly to a fixed point of $T$. Moreover, they introduced and studied an iteration process of a nonexpansive semigroup $\tau=\{T(t): 0 \leq$ $t<\infty\}$ in a Hilbert space $H$ :

$x_{0} \in C$, chosen arbitrarily,

$$
\begin{gathered}
y_{n}=\alpha_{n} x_{n}+\left(1-\alpha_{n}\right) \frac{1}{t_{n}} \int_{0}^{t_{n}} T(u) x_{n} d u, \\
C_{n}=\left\{v \in C:\left\|y_{n}-v\right\| \leq\left\|x_{n}-v\right\|\right\}, \\
Q_{n}=\left\{v \in C:\left\langle x_{n}-v, x_{n}-x_{0}\right\rangle \geq 0\right\}, \\
x_{n+1}=P_{C_{n} \cap Q_{n}}\left(x_{0}\right) .
\end{gathered}
$$


In 2006, Kim and $\mathrm{Xu}$ [4] adapted iteration (1.4) to an asymptotically nonexpansive mapping in a Hilbert space $H$ :

$$
\begin{gathered}
x_{0} \in C, \quad \text { chosen arbitrarily, } \\
y_{n}=\alpha_{n} x_{n}+\left(1-\alpha_{n}\right) T^{n} x_{n}, \\
C_{n}=\left\{v \in C:\left\|y_{n}-v\right\|^{2} \leq\left\|x_{n}-v\right\|^{2}+\theta_{n}\right\}, \\
Q_{n}=\left\{v \in C:\left\langle x_{n}-v, x_{n}-x_{0}\right\rangle \geq 0\right\}, \\
x_{n+1}=P_{C_{n} \cap Q_{n}}\left(x_{0}\right),
\end{gathered}
$$

where $\theta_{n}=\left(1-\alpha_{n}\right)\left(k_{n}^{2}-1\right)(\operatorname{diam} C)^{2} \rightarrow 0$ as $n \rightarrow \infty$. They also proved that if $\alpha_{n} \leq a$ for all $n$ and for some $0<a<1$, then the sequence $\left\{x_{n}\right\}$ converges weakly to a fixed point of $T$. Moreover, they modified an iterative method (1.5) to the case of an asymptotically nonexpansive semigroup $\tau=\{T(t): 0 \leq t<\infty\}$ in a Hilbert space $H$ :

$$
\begin{gathered}
x_{0} \in C, \quad \text { chosen arbitrarily, } \\
y_{n}=\alpha_{n} x_{n}+\left(1-\alpha_{n}\right) \frac{1}{t_{n}} \int_{0}^{t_{n}} T(u) x_{n} d u, \\
C_{n}=\left\{v \in C:\left\|y_{n}-v\right\|^{2} \leq\left\|x_{n}-v\right\|^{2}+\theta_{n}\right\}, \\
Q_{n}=\left\{v \in C:\left\langle x_{n}-v, x_{n}-x_{0}\right\rangle \geq 0\right\}, \\
x_{n+1}=P_{C_{n} \cap Q_{n}}\left(x_{0}\right),
\end{gathered}
$$

where $\theta_{n}=\left(1-\alpha_{n}\right)\left[\left(\left(1 / t_{n}\right) \int_{0}^{t_{n}} L_{u} d u\right)^{2}-1\right](\operatorname{diam} C)^{2} \rightarrow 0$ as $n \rightarrow \infty$.

In 2007, Zegeye and Shahzad [5] developed the iteration process for a finite family of asymptotically nonexpansive mappings and asymptotically nonexpansive semigroups with $C$ a closed convex bounded subset of a Hilbert space $H$ :

$$
\begin{gathered}
x_{0} \in C, \quad \text { chosen arbitrarily, } \\
y_{n}=\alpha_{n 0} x_{n}+\alpha_{n 1} T_{1}^{n} x_{n}+\alpha_{n 2} T_{2}^{n} x_{n}+\cdots+\alpha_{n r} T_{r}^{n} x_{n}, \\
C_{n}=\left\{v \in C:\left\|y_{n}-v\right\|^{2} \leq\left\|x_{n}-v\right\|^{2}+\theta_{n}\right\} \\
Q_{n}=\left\{v \in C:\left\langle x_{n}-v, x_{n}-x_{0}\right\rangle \geq 0\right\} \\
x_{n+1}=P_{C_{n} \cap Q_{n}}\left(x_{0}\right)
\end{gathered}
$$


where $\theta_{n}=\left[\left(k_{n 1}^{2}-1\right) \alpha_{n 1}+\left(k_{n 2}^{2}-1\right) \alpha_{n 2}+\cdots+\left(k_{n r}^{2}-1\right) \alpha_{n r}\right](\operatorname{diam} C)^{2} \rightarrow 0$ as $n \rightarrow \infty$ and

$x_{0} \in C, \quad$ chosen arbitrarily,

$$
\begin{gathered}
y_{n}=\alpha_{n 0} x_{n}+\alpha_{n 1}\left(\frac{1}{t_{n 1}} \int_{0}^{t_{n 1}} T_{1}(u) x_{n} d u\right)+\left(\frac{1}{t_{n 2}} \int_{0}^{t_{n 2}} T_{2}(u) x_{n} d u\right)+\cdots+\left(\frac{1}{t_{n r}} \int_{0}^{t_{n r}} T_{r}(u) x_{n} d u\right) \\
C_{n}=\left\{v \in C:\left\|y_{n}-v\right\|^{2} \leq\left\|x_{n}-v\right\|^{2}+\tilde{\theta}_{n}\right\} \\
Q_{n}=\left\{v \in C:\left\langle x_{n}-v, x_{n}-x_{0}\right\rangle \geq 0\right\} \\
x_{n+1}=P_{C_{n} \cap Q_{n}}\left(x_{0}\right)
\end{gathered}
$$

where $\tilde{\theta}_{n}=\left[\left(L_{u 1}^{2}-1\right) \alpha_{n 1}+\left(L_{u 2}^{2}-1\right) \alpha_{n 2}+\cdots+\left(L_{u r}^{2}-1\right) \alpha_{n r}\right](\operatorname{diam} C)^{2} \rightarrow 0$ as $n \rightarrow \infty$, with $L_{u i}=\left(1 / t_{n i}\right) \int_{0}^{t_{n i}} L_{u}^{T i} d u$, for each $i=1,2,3, \ldots, r$.

Recently, Su and Qin [6] modified the hybrid iteration method of Nakajo and Takahashi through the monotone hybrid method, and to prove strong convergence theorems.

In 2008, Takahashi et al. [7] proved strong convergence theorems by the new hybrid methods for a family of nonexpansive mappings and nonexpansive semigroups in Hilbert spaces:

$$
\begin{gathered}
y_{n}=\alpha_{n} u_{n}+\left(1-\alpha_{n}\right) T_{n} x_{n}, \\
C_{n+1}=\left\{v \in C_{n}:\left\|y_{n}-v\right\| \leq\left\|u_{n}-v\right\|\right\}, \\
x_{n+1}=P_{C_{n+1}}\left(x_{0}\right), \quad n \in \mathbb{N},
\end{gathered}
$$

where $0 \leq \alpha_{n} \leq a<1$, and

$$
\begin{gathered}
y_{n}=\alpha_{n} u_{n}+\left(1-\alpha_{n}\right) \frac{1}{\lambda_{n}} \int_{0}^{\lambda_{n}} T(s) u_{n} d s, \\
C_{n+1}=\left\{v \in C_{n}:\left\|y_{n}-v\right\| \leq\left\|u_{n}-v\right\|\right\}, \\
x_{n+1}=P_{C_{n+1}}\left(x_{0}\right), \quad n \in \mathbb{N},
\end{gathered}
$$

where $0 \leq \alpha_{n} \leq a<1,0<\lambda_{n}<\infty$ and $\lambda_{n} \rightarrow \infty$.

In this paper, motivated and inspired by the above results, we modify iteration process (1.4)-(1.11) by the new hybrid methods for countable families of asymptotically nonexpansive mappings and semigroups in a Hilbert space, and to prove strong convergence theorems. Our results presented are improvement and extension of the corresponding results in $[3,5-8]$ and many authors.

\section{Preliminaries}

This section collects some lemmas which will be used in the proofs for the main results in the next section. 
Lemma 2.1. Here holds the identity in a Hilbert space $H$ :

$$
\|\lambda x+(1-\lambda) y\|^{2}=\lambda\|x\|^{2}+(1-\lambda)\|y\|^{2}-\lambda(1-\lambda)\|x-y\|^{2}
$$

for all $x, y \in H$ and $\lambda \in[0,1]$.

Using this Lemma 2.1, we can prove that the set $F(T)$ of fixed points of $T$ is closed and convex. Let $C$ be a nonempty closed convex subset of $H$. Then, for any $x \in H$, there exists a unique nearest point in $C$, denoted by $P_{C}(x)$, such that $\left\|x-P_{C} x\right\| \leq\|x-y\|$ for all $y \in C$, where $P_{C}$ is called the metric projection of $H$ onto $C$. We know that for $x \in H$ and $z \in C, z=P_{C} x$ is equivalent to $\langle x-z, z-u\rangle \geq 0$ for all $u \in C$. We know that a Hilbert space $H$ satisfies Opial's condition, that is, for any sequence $\left\{x_{n}\right\} \subset H$ with $x_{n} \rightarrow x$, the inequality

$$
\liminf _{n \rightarrow \infty}\left\|x_{n}-x\right\|<\liminf _{n \rightarrow \infty}\left\|x_{n}-y\right\|
$$

hold for every $y \in H$ with $y \neq H$. We also know that $H$ has the Kadec-Klee property, that is, $x_{n} \rightarrow x$ and $\left\|x_{n}\right\| \rightarrow\|x\|$ imply $x_{n} \rightarrow x$. In fact, from

$$
\left\|x_{n}-x\right\|^{2}=\|x\|^{2}-2\left\langle x_{n}, x\right\rangle+\|x\|^{2}
$$

we get that a Hilbert space has the Kadec-Klee property.

Let $C$ be a nonempty closed convex subset of a Hilbert space $H$. Motivated by Nakajo et al. [9], we give the following definitions: Let $\left\{T_{n}\right\}$ and $\tau$ be families of nonexpansive mappings of $C$ into itself such that $\emptyset \neq F(\tau) \subset \bigcap_{n=1}^{\infty} F\left(T_{n}\right)$, where $F\left(T_{N}\right)$ is the set of all fixed points of $T_{n}$ and $F(\tau)$ is the set of all common fixed points of $\tau$. We consider the following conditions of $\left\{T_{n}\right\}$ and $\tau$ (see [9]):

(i) NST-condition (I). For each bounded sequence $\left\{z_{n}\right\} \subset C, \lim _{n \rightarrow \infty}\left\|z_{n}-T_{n} z_{n}\right\|=0$ implies that $\lim _{n \rightarrow \infty}\left\|z_{n}-T z_{n}\right\|=0$ for all $T \in \tau$.

(ii) NST-condition (II). For each bounded sequence $\left\{z_{n}\right\} \subset C, \lim _{n \rightarrow \infty}\left\|z_{n+1}-T_{n} z_{n}\right\|=0$ implies that $\lim _{n \rightarrow \infty}\left\|z_{n}-T_{m} z_{n}\right\|=0$ for all $m \in \mathbb{N}$.

(iii) NST-condition (III). There exists $\left\{a_{n}\right\} \subset[0, \infty)$ with $\sum_{n=1}^{\infty} a_{n}<\infty$ such that for every bounded subset $B$ of $C$, there exists $M_{B}>0$ such that $\left\|T_{n} x-T_{n+1} x\right\| \leq a_{n} M_{B}$ holds for all $n \in \mathbb{N}$ and $x \in B$.

Lemma 2.2. Let $C$ be a nonempty closed convex subset of $E$ and let $T$ be a nonexpansive mapping of $C$ into itself with $F(T) \neq \emptyset$. Then, the following hold:

(i) $\left\{T_{n}\right\}$ with $T_{n}=T(\forall n \in \mathbb{N})$ and $\tau=\{T\}$ satisfy the condition (I) with $\bigcap_{n=1}^{\infty} F\left(T_{n}\right)=$ $F(\tau)=F(T)$.

(ii) $\left\{T_{n}\right\}$ with $T_{n}=T(\forall n \in \mathbb{N})$ and $\tau=\{T\}$ satisfy the condition (I) with $\alpha_{n}=0(\forall n \in \mathbb{N})$.

Lemma 2.3 (Opial [10]). Let $C$ be a closed convex subset of a real Hilbert space $H$ and let $T: C \rightarrow C$ be a nonexpansive mapping such that $F(T) \neq \emptyset$. If $\left\{x_{n}\right\}$ is a sequence in $C$ such that $x_{n} \rightarrow z$ and $x_{n}-T x_{n} \rightarrow 0$, then $z=T z$. 
Lemma 2.4 (Lin et al. [11]). Let $T$ be an asymptotically nonexpansive mapping defined on a bounded closed convex subset of a bounded closed convex subset $C$ of a Hilbert space $H$. If $\left\{x_{n}\right\}$ is a sequence in $C$ such that $x_{n} \rightarrow z$ and $T x_{n}-x_{n} \rightarrow 0$, then $z \in F(T)$.

Lemma 2.5 (Nakajo and Takahashi [3]). Let $H$ be a real Hilbert space. Given a closed convex subset $C \subset H$ and points $x, y, z \in H$. Given also a real number $a \in \mathbb{R}$. The set $D:=\{v \in C$ : $\left.\|y-v\|^{2} \leq\|x-v\|^{2}+\langle z, v\rangle+a\right\}$ is convex and closed.

Lemma 2.6 (Kim and $\mathrm{Xu}[4])$. Let $C$ be a nonempty bounded closed convex subset of $H$ and $\tau=$ $\{T(t): 0 \leq t<\infty\}$ be an asymptotically nonexpansive semigroup on $C$. If $\left\{x_{n}\right\}$ is a sequence in $C$ satisfying the properties

(a) $x_{n} \rightarrow z$;

(b) $\limsup \sup _{t \rightarrow \infty} \lim \sup _{n \rightarrow \infty}\left\|T(t) x_{n}-x_{n}\right\|=0$,

then $z \in F(\tau)$.

Lemma 2.7 (Kim and $\mathrm{Xu}[4]$ ). Let $C$ be a nonempty bounded closed convex subset of $H$ and $\tau=$ $\{T(t): 0 \leq t<\infty\}$ be an asymtotically nonexpansive semigroup on $C$. Then it holds that

$$
\limsup _{s \rightarrow \infty} \limsup _{t \rightarrow \infty} \sup _{x \in C}\left\|\frac{1}{t} \int_{0}^{t} T(u) x d u-T(s)\left(\frac{1}{t} \int_{0}^{t} T(u) x d u\right)\right\|=0 .
$$

\section{Strong Convergence for a Family of Asymptotically Nonexpansive Mappings}

Theorem 3.1. Let $C$ be a nonempty bounded closed convex subset of a Hilbert space $H$ and let $T_{i}$ : $C \rightarrow C$ for $i=1,2,3, \ldots$ be a countable family of asymptotically nonexpansive mapping with sequence $\left\{t_{n i}\right\}_{n \geq 0}$ for $i=1,2,3, \ldots$, respectively. Assume $\left\{\alpha_{n}\right\}_{n \geq 0} \subset(0,1)$ such that $\alpha_{n} \leq a<1$ for all $n$ and $\alpha_{n} \rightarrow 0$ as $n \rightarrow \infty$. Let $F(\tau)=\bigcap_{i=1}^{\infty} F\left(T_{i}\right) \neq \emptyset$. Further, suppose that $\left\{T_{i}\right\}$ satisfies NST-condition (I) and (III) with T. Define a sequence $\left\{x_{n}\right\}$ in $C$ by the following algorithm:

$$
\begin{gathered}
x_{0}=x \in C, \quad C_{0}=C, \\
y_{n}=\alpha_{n} x_{n}+\left(1-\alpha_{n}\right) T_{i}^{n} x_{n}, \\
C_{n+1}=\left\{v \in C_{n}:\left\|y_{n}-v\right\|^{2} \leq\left\|x_{n}-v\right\|^{2}+\theta_{n}\right\}, \\
x_{n+1}=P_{C_{n+1}}(x), \quad n=0,1,2 \ldots
\end{gathered}
$$

where $\theta_{n}=\left(1-\alpha_{n}\right)\left(t_{n i}^{2}-1\right)(\operatorname{diam} C)^{2} \rightarrow 0$ as $n \rightarrow \infty$. Then $\left\{x_{n}\right\}$ converges in norm to $P_{F(\tau)}\left(x_{0}\right)$.

Proof. We first show that $C_{n+1}$ is closed and convex for all $n \in \mathbb{N} \cup\{0\}$. From the Lemma 2.5, it is observed that $C_{n+1}$ is closed and convex for each $n \in \mathbb{N} \cup\{0\}$. 
Fixed Point Theory and Applications

Next, we show that $F(\tau) \subset C_{n}$ for all $n \geq 0$. Indeed, let $p \in F(\tau)$, we have

$$
\begin{aligned}
\left\|y_{n}-p\right\|^{2} & =\left\|\alpha_{n} x_{n}+\left(1-\alpha_{n}\right) T_{i}^{n} x_{n}-p\right\|^{2} \\
& =\left\|\alpha_{n}\left(x_{n}-p\right)+\left(1-\alpha_{n}\right)\left(T_{i}^{n} x_{n}-p\right)\right\|^{2} \\
& \leq \alpha_{n}\left\|x_{n}-p\right\|^{2}+\left(1-\alpha_{n}\right)\left\|T_{i}^{n} x_{n}-p\right\|^{2} \\
& \leq \alpha_{n}\left\|x_{n}-p\right\|^{2}+\left(1-\alpha_{n}\right) t_{n i}^{2}\left\|x_{n}-p\right\|^{2} \\
& =\left\|x_{n}-p\right\|^{2}+\left(1-\alpha_{n}\right)\left(t_{n i}^{2}\left\|x_{n}-p\right\|^{2}-\left\|x_{n}-p\right\|^{2}\right) \\
& =\left\|x_{n}-p\right\|^{2}+\left(1-\alpha_{n}\right)\left(t_{n i}^{2}-1\right)\left\|x_{n}-p\right\|^{2} \\
& =\left\|x_{n}-p\right\|^{2}+\theta_{n} \longrightarrow 0 \quad \text { as } n \longrightarrow \infty .
\end{aligned}
$$

Thus $p \in C_{n+1}$ and hence $F(\tau) \subset C_{n+1}$ for all $n \geq 0$. Thus $\left\{x_{n}\right\}$ is well defined.

From $x_{n}=P_{C_{n}} x_{0}$ and $x_{n+1}=P_{C_{n+1}} x_{0} \in C_{n+1} \subset C_{n}$, we have

$$
\left\langle x_{0}-x_{n}, x_{n}-x_{n+1}\right\rangle \geq 0 \quad \forall x_{0} \in F(\tau), n \in \mathbb{N} \cup\{0\} .
$$

So, for $x_{n+1} \in C_{n}$, we have

$$
\begin{aligned}
0 & \leq\left\langle x_{0}-x_{n}, x_{n}-x_{n+1}\right\rangle \\
& =\left\langle x_{0}-x_{n}, x_{n}-x_{0}+x_{0}-x_{n+1}\right\rangle, \\
& =-\left\langle x_{n}-x_{0}, x_{n}-x_{0}\right\rangle+\left\langle x_{0}-x_{n}, x_{0}-x_{n+1}\right\rangle, \\
& \leq-\left\|x_{n}-x_{0}\right\|^{2}+\left\|x_{0}-x_{n}\right\|\left\|x_{0}-x_{n+1}\right\|
\end{aligned}
$$

for all $n \in \mathbb{N}$. This implies that

$$
\left\|x_{0}-x_{n}\right\|^{2} \leq\left\|x_{0}-x_{n}\right\|\left\|x_{0}-x_{n+1}\right\|
$$

hence

$$
\left\|x_{0}-x_{n}\right\| \leq\left\|x_{0}-x_{n+1}\right\|
$$

for all $n \in \mathbb{N} \cup\{0\}$. Therefore $\left\{\left\|x_{0}-x_{n}\right\|\right\}$ is nondecreasing.

From $x_{n}=P_{C_{n}} x_{0}$, we have

$$
\left\langle x_{0}-x_{n}, x_{n}-y\right\rangle \geq 0 \quad \forall y \in C_{n}
$$

Using $F(\tau) \subset C_{n}$, we also have

$$
\left\langle x_{0}-x_{n}, x_{n}-p\right\rangle \geq 0 \quad \forall p \in F(T), n \in \mathbb{N} \cup\{0\} .
$$


So, for $p \in F(\tau)$, we have

$$
\begin{aligned}
0 & \geq\left\langle x_{0}-x_{n}, x_{n}-p\right\rangle, \\
& =\left\langle x_{0}-x_{n}, x_{n}-x_{0}+x_{0}-p\right\rangle, \\
& =-\left\|x_{0}-x_{n}\right\|^{2}+\left\|x_{0}-x_{n}\right\|\left\|x_{0}-p\right\| .
\end{aligned}
$$

This implies that

$$
\left\|x_{0}-x_{n}\right\| \leq\left\|x_{0}-p\right\| \quad \forall p \in F(\tau), n \in \mathbb{N} \cup\{0\}
$$

Thus, $\left\{\left\|x_{0}-x_{n}\right\|\right\}$ is bounded. So, $\lim _{n \rightarrow \infty}\left\|x_{n}-x_{0}\right\|$ exists.

Next, we show that $\left\|x_{n+1}-x_{n}\right\| \rightarrow 0$. From (3.3), we have

$$
\begin{aligned}
\left\|x_{n}-x_{n+1}\right\|^{2} & =\left\|x_{n}-x_{0}+x_{0}-x_{n+1}\right\|^{2} \\
& =\left\|x_{n}-x_{0}\right\|^{2}+2\left\langle x_{n}-x_{0}, x_{0}-x_{n+1}\right\rangle+\left\|x_{0}-x_{n+1}\right\|^{2} \\
& =\left\|x_{n}-x_{0}\right\|^{2}+2\left\langle x_{n}-x_{0}, x_{0}-x_{n}+x_{n}-x_{n+1}\right\rangle+\left\|x_{0}-x_{n+1}\right\|^{2} \\
& =\left\|x_{n}-x_{0}\right\|^{2}-2\left\langle x_{0}-x_{n}, x_{0}-x_{n}\right\rangle-2\left\langle x_{0}-x_{n}, x_{n}-x_{n+1}\right\rangle+\left\|x_{0}-x_{n+1}\right\|^{2} \\
& \leq\left\|x_{n}-x_{0}\right\|^{2}-2\left\|x_{n}-x_{0}\right\|^{2}+\left\|x_{0}-x_{n+1}\right\|^{2} \\
& =-\left\|x_{n}-x_{0}\right\|^{2}+\left\|x_{0}-x_{n+1}\right\|^{2} .
\end{aligned}
$$

Since $\lim _{n \rightarrow \infty}\left\|x_{n}-x_{0}\right\|$ exists, we conclude that $\lim _{n \rightarrow \infty}\left\|x_{n}-x_{n+1}\right\|=0$.

Since $x_{n+1} \in C_{n+1} \subset C_{n}$, we have $\left\|y_{n}-x_{n+1}\right\|^{2} \leq\left\|x_{n}-x_{n+1}\right\|^{2}+\theta_{n}$ which implies that $\left\|y_{n}-x_{n+1}\right\| \leq\left\|x_{n}-x_{n+1}\right\|+\sqrt{\theta_{n}}$. Now we claim that $\left\|T_{i} x_{n}-x_{n}\right\| \rightarrow 0$ as $n \rightarrow \infty$ for all $i \in \mathbb{N}$. We first show that $\left\|T_{i}^{n} x_{n}-x_{n}\right\| \rightarrow 0$ as $n \rightarrow \infty$. Indeed, by the definition of $y_{n}$, we have

$$
\begin{aligned}
\left\|y_{n}-x_{n}\right\| & =\left\|\alpha_{n} x_{n}+\left(1-\alpha_{n}\right) T_{i}^{n} x_{n}-x_{n}\right\|, \\
& =\left\|\left(1-\alpha_{n}\right) T_{i}^{n} x_{n}+\left(1-\alpha_{n}\right) x_{n}\right\|, \\
& =\left\|\left(1-\alpha_{n}\right)\left(T_{i}^{n} x_{n}-x_{n}\right)\right\|, \\
& =\left(1-\alpha_{n}\right)\left\|T_{i}^{n} x_{n}-x_{n}\right\|
\end{aligned}
$$

for all $i \in \mathbb{N}$ and it follows that

$$
\begin{aligned}
\left\|T_{i}^{n} x_{n}-x_{n}\right\| & =\frac{1}{1-\alpha_{n}}\left\|y_{n}-x_{n}\right\| \\
& \leq \frac{1}{1-\alpha_{n}}\left(\left\|y_{n}-x_{n+1}\right\|+\left\|x_{n+1}-x_{n}\right\|\right) \\
& \leq \frac{1}{1-\alpha_{n}}\left(\left\|x_{n}-x_{n+1}\right\|+\sqrt{\theta_{n}}+\left\|x_{n+1}-x_{n}\right\|\right) .
\end{aligned}
$$


Fixed Point Theory and Applications

Since $\left\|x_{n}-x_{n+1}\right\| \rightarrow 0$ as $n \rightarrow \infty$, we obtain

$$
\lim _{n \rightarrow \infty}\left\|T_{i}^{n} x_{n}-x_{n}\right\|=0
$$

for all $i \in \mathbb{N}$.

Let $t_{\infty}=\sup \left\{t_{n}: n \geq 1\right\}<\infty$. Now, for $i=1,2,3, \ldots$, we get

$$
\begin{aligned}
\left\|T_{i} x_{n}-x_{n}\right\| & \leq\left\|T_{i} x_{n}-T_{i}^{n+1} x_{n}\right\|+\left\|T_{i}^{n+1} x_{n}-T_{i}^{n+1} x_{n+1}\right\|+\left\|T_{i}^{n+1} x_{n+1}-x_{n+1}\right\|+\left\|x_{n+1}-x_{n}\right\|, \\
& \leq t_{\infty}\left\|x_{n}-T_{i}^{n} x_{n}\right\|+\left\|T_{i}^{n+1} x_{n+1}-x_{n+1}\right\|+\left(1+t_{\infty}\right)\left\|x_{n}-x_{n+1}\right\|,
\end{aligned}
$$

from (3.14) and $\left\|x_{n}-x_{n+1}\right\| \rightarrow 0$ as $n \rightarrow \infty$, yields

$$
\lim _{n \rightarrow \infty}\left\|x_{n}-T_{i} x_{n}\right\|=0
$$

for each $i=1,2,3, \ldots$ Let $m \in \mathbb{N}$ and take $n \in \mathbb{N}$ with $i>n$. By NST-condition (III), there exists $M_{B}>0$ such that

$$
\begin{aligned}
\left\|T_{n} x_{n}-x_{n}\right\| & \leq\left\|T_{n} x_{n}-T_{i} x_{n}\right\|+\left\|T_{i} x_{n}-x_{n}\right\| \\
& \leq\left\|T_{n} x_{n}-T_{n+1} x_{n}\right\|+\left\|T_{n+1} x_{n}-T_{n+2} x_{n}\right\|+\cdots+\left\|T_{i-1} x_{n}-T_{i} x_{n}\right\|+\left\|T_{i} x_{n}-x_{n}\right\| \\
& \leq M_{B} \sum_{k=n}^{i-1} a_{k}+\left\|T_{i} x_{n}-x_{n}\right\| .
\end{aligned}
$$

By (3.16) and $\sum_{k=n}^{i-1} a_{k}<\infty$, we get

$$
\limsup _{n \rightarrow \infty}\left\|x_{n}-T_{n} x_{n}\right\|=0
$$

By the assumption of $\left\{T_{n}\right\}$ and NST-condition (I), we have

$$
\left\|T x_{n}-x_{n}\right\| \longrightarrow 0 \quad \text { as } n \longrightarrow \infty \text {. }
$$

Put $z_{0}=P_{F(T)} x_{0}$. Since $\left\|x_{n}-x_{0}\right\| \leq\left\|z_{0}-x_{0}\right\|$ for all $n \in \mathbb{N} \cup\{0\},\left\{x_{n}\right\}$ is bounded. Let $\left\{x_{n_{i}}\right\}$ be a subsequence of $\left\{x_{n}\right\}$ such that $x_{n_{i}} \rightarrow w$. Since $C$ is closed and convex, $C$ is weakly closed and 
hence $w \in C$. From (3.19), we have that $w=T w$. If not, since $H$ satisfies Opial's condition, we have

$$
\begin{aligned}
\liminf _{n \rightarrow \infty}\left\|x_{n_{i}}-w\right\| & \leq \liminf _{n \rightarrow \infty}\left\|x_{n_{i}}-T w\right\|, \\
& \leq \liminf _{n \rightarrow \infty}\left(\left\|x_{n_{i}}-T x_{n_{i}}\right\|+\left\|T x_{n_{i}}-T w\right\|\right), \\
& \leq \liminf _{n \rightarrow \infty}\left(\left\|x_{n_{i}}-T x_{n_{i}}\right\|+\left\|x_{n_{i}}-w\right\|\right), \\
& =\liminf _{n \rightarrow \infty}\left\|x_{n_{i}}-w\right\| .
\end{aligned}
$$

This is a contradiction. So, we have that $w=T w$. Then, we have

$$
\left\|x_{0}-z_{0}\right\| \leq\left\|x_{0}-w\right\| \leq \liminf _{\mathrm{i} \rightarrow \infty}\left\|x_{0}-x_{n_{i}}\right\| \leq \limsup _{\mathrm{i} \rightarrow \infty}\left\|x_{0}-x_{n_{i}}\right\| \leq\left\|z_{0}-x_{0}\right\|
$$

and hence $\left\|x_{0}-z_{0}\right\|=\left\|x_{0}-w\right\|$. From $z_{0}=P_{F}\left(x_{0}\right)$, we have $z_{0}=w$. This implies that $\left\{x_{n}\right\}$ converges weakly to $z_{0}$, and we have

$$
\left\|x_{0}-z_{0}\right\| \leq \liminf _{n \rightarrow \infty}\left\|x_{0}-x_{n}\right\| \leq \limsup _{n \rightarrow \infty}\left\|x_{0}-x_{n}\right\| \leq\left\|z_{0}-x_{0}\right\|
$$

and hence $\lim _{n \rightarrow \infty}\left\|x_{0}-x_{n}\right\|=\left\|z_{0}-x_{0}\right\|$. From $x_{n} \rightarrow z_{0}$, we also have $x_{0}-x_{n}-x_{0}-z_{0}$. Since $H$ satisfies the Kadec-Klee property, it follows that $x_{0}-x_{n} \rightarrow x_{0}-z_{0}$. So, we have

$$
\left\|x_{n}-z_{0}\right\|=\left\|x_{n}-x_{0}-\left(z_{0}-x_{0}\right)\right\| \longrightarrow 0
$$

and hence $x_{n} \rightarrow z_{0}=P_{F}\left(x_{0}\right)$. This completes the proof.

Corollary 3.2. Let $C$ be a nonempty bounded closed convex subset of a Hilbert space $H$ and let $T$ : $C \rightarrow C$ be an asymptotically nonexpansive mapping with sequence $\left\{t_{n}\right\}_{n \geq 0}$. Assume $\left\{\alpha_{n}\right\}_{n \geq 0} \subset(0,1)$ such that $\alpha_{n} \leq a<1$ for all $n$ and $\alpha_{n} \rightarrow 0$ as $n \rightarrow \infty$. Let $F(T) \neq \emptyset$. Define a sequence $\left\{x_{n}\right\}$ in $C$ by the following algorithm:

$$
\begin{gathered}
x_{0}=x \in C, \quad C_{0}=C, \\
y_{n}=\alpha_{n} x_{n}+\left(1-\alpha_{n}\right) T^{n} x_{n}, \\
C_{n+1}=\left\{v \in C_{n}:\left\|y_{n}-v\right\|^{2} \leq\left\|x_{n}-v\right\|^{2}+\theta_{n}\right\}, \\
x_{n+1}=P_{C_{n+1}}(x), \quad n=0,1,2 \ldots,
\end{gathered}
$$

where $\theta_{n}=\left(1-\alpha_{n}\right)\left(t_{n}^{2}-1\right)(\operatorname{diam} C)^{2} \rightarrow 0$ as $n \rightarrow \infty$. Then $\left\{x_{n}\right\}$ converges in norm to $P_{F(T)}\left(x_{0}\right)$. Proof. Setting $T_{i}^{n} \equiv T^{n}$ for all $i \in \mathbb{N} \cup\{0\}$ from Lemma 2.2(i) and Theorem 3.1, we immediately obtain the corollary. 
Since every family's nonexpansive mapping is family's asymptotically nonexpansive mapping we obtain the following result.

Corollary 3.3. Let $C$ be a nonempty bounded closed convex subset of a Hilbert space $H$ and let $\left\{T_{i}\right\}: C \rightarrow C$ be a family of nonexpansive mappings with sequence $\left\{t_{i}\right\}_{i \geq 0}$. Assume $\left\{\alpha_{n}\right\}_{n \geq 0} \subset(0,1)$ such that $\alpha_{n} \leq a<1$ for all $n$ and $\alpha_{n} \rightarrow 0$ as $n \rightarrow \infty$. Let $F(\tau)=\bigcap_{i=1}^{\infty} F\left(T_{i}\right) \neq \emptyset$. Further, suppose that $\left\{T_{i}\right\}$ satisfies NST-condition (I) with T. Define a sequence $\left\{x_{n}\right\}$ in $C$ by the following algorithm:

$$
\begin{gathered}
x_{0}=x \in C, \quad C_{0}=C, \\
y_{n}=\alpha_{n} x_{n}+\left(1-\alpha_{n}\right) T_{i} x_{n}, \\
C_{n+1}=\left\{v \in C_{n}:\left\|y_{n}-v\right\|^{2} \leq\left\|x_{n}-v\right\|^{2}\right\}, \\
x_{n+1}=P_{C_{n+1}}(x), \quad n=0,1,2 \ldots
\end{gathered}
$$

Assume that if for each bounded sequence $\left\{z_{n}\right\} \in C, \lim _{n \rightarrow \infty}\left\|z_{n}-T_{i} z_{n}\right\|=0$, for all $i \in \mathbb{N}$ implies that $\lim _{n \rightarrow \infty}\left\|z_{n}-T z_{n}\right\|=0$. Then $\left\{x_{n}\right\}$ converges in norm to $P_{F(\tau)}\left(x_{0}\right)$.

We have the following corollary for nonexpansive mappings by Lemma 2.2(i) and Theorem 3.1.

Corollary 3.4 (Takahashi et al. [7, Theorem 4.1]). Let $C$ be a bounded closed convex subset of a Hilbert space $H$ and let $T: C \rightarrow C$ be a nonexpansive mapping such that $F(T) \neq \emptyset$. Assume that $0 \leq \alpha_{n} \leq a<1$ for all $n$. Then the sequence $\left\{x_{n}\right\}$ generated by

$$
\begin{gathered}
x_{0}=x \in C, \quad C_{0}=C, \\
y_{n}=\alpha_{n} x_{n}+\left(1-\alpha_{n}\right) T x_{n}, \\
C_{n+1}=\left\{v \in C_{n}:\left\|y_{n}-v\right\| \leq\left\|x_{n}-v\right\|\right\}, \\
x_{n+1}=P_{C_{n+1}}(x), \quad n=0,1,2 \ldots,
\end{gathered}
$$

converges in norm to $P_{F(T)} x_{0}$.

\section{Strong Convergence for a Family of Asymptotically Nonexpansive Semigroups}

Theorem 4.1. Let $C$ be a nonempty bounded closed convex subset of a Hilbert space $H$ and let $\tau_{i}=\left\{T_{i}(t): t \in \mathbb{R}^{+}, i=1,2,3, \ldots\right\}$ be a countable family of asymptotically nonexpansive semigroups. Assume $\left\{\alpha_{n}\right\}_{n \geq 0} \subset(0,1)$ such that $\alpha_{n} \leq a<1$ for all $n$ and $\alpha_{n} \rightarrow 0$ as $n \rightarrow \infty$. Let 
$\left\{t_{n i}\right\}, i=1,2,3, \ldots$ be a countable positive and divergent real sequence. Let $F=\bigcap_{i=1}^{\infty} F\left(\tau_{i}\right) \neq \emptyset$. Further, suppose that $\left\{T_{i}\right\}$ satisfies NST-condition (I) with T. Define a sequence $\left\{x_{n}\right\}$ in C by the following algorithm:

$$
\begin{gathered}
x_{0}=x \in C, \quad C_{0}=C, \\
y_{n}=\alpha_{n} x_{n}+\left(1-\alpha_{n}\right) \frac{1}{t_{n i}} \int_{0}^{t_{n i}} T_{i}(u) x_{n} d u, \\
C_{n+1}=\left\{v \in C_{n}:\left\|y_{n}-v\right\|^{2} \leq\left\|x_{n}-v\right\|^{2}+\tilde{\theta}_{n}\right\}, \\
x_{n+1}=P_{C_{n+1}}(x), \quad n=0,1,2 \ldots,
\end{gathered}
$$

where $\tilde{\theta}_{n}=\left(1-\alpha_{n}\right)\left(\tilde{t}_{n i}^{2}-1\right)(\operatorname{diam} C)^{2} \rightarrow 0$ as $n \rightarrow \infty$ with $\tilde{t}_{n i}=\left(1 / t_{n i}\right) \int_{0}^{t_{n i}} L_{u}^{T_{i}} d u$. Then $\left\{x_{n}\right\}$ converges in norm to $P_{F}\left(x_{0}\right)$.

Proof. First observe that $F \subset C_{n}$ for all $n$. Indeed, we have for all $p \in F$

$$
\begin{aligned}
\left\|y_{n}-p\right\|^{2} & =\left\|\alpha_{n} x_{n}+\left(1-\alpha_{n}\right) \frac{1}{t_{n i}} \int_{0}^{t_{n i}} T_{i}(u) x_{n} d u-p\right\|^{2} \\
& =\left\|\alpha_{n}\left(x_{n}-p\right)+\left(1-\alpha_{n}\right)\left(\frac{1}{t_{n i}} \int_{0}^{t_{n i}} T_{i}(u) x_{n} d u-p\right)\right\|^{2} \\
& \leq \alpha_{n}\left\|x_{n}-p\right\|^{2}+\left(1-\alpha_{n}\right)\left\|\frac{1}{t_{n i}} \int_{0}^{t_{n i}} T_{i}(u) x_{n} d u-p\right\|^{2} \\
& \leq \alpha_{n}\left\|x_{n}-p\right\|^{2}+\left(1-\alpha_{n}\right)\left(\frac{1}{t_{n i}} \int_{0}^{t_{n i}}\left\|T_{i}(u) x_{n}-p\right\| d u\right)^{2} \\
& \leq \alpha_{n}\left\|x_{n}-p\right\|^{2}+\left(1-\alpha_{n}\right)\left(\frac{1}{t_{n i}} \int_{0}^{t_{n i}} L_{u}^{T i} d u\right)\left\|x_{n}-p\right\|^{2} \\
& =\alpha_{n}\left\|x_{n}-p\right\|^{2}+\left(1-\alpha_{n}\right)\left(\tilde{t}_{n i}^{2}\left\|x_{n}-p\right\|^{2}\right) \\
& \leq\left\|x_{n}-p\right\|^{2}+\left(1-\alpha_{n}\right)\left(\tilde{t}_{n i}^{2}-1\right)\left\|x_{n}-p\right\|^{2} \\
& \leq\left\|x_{n}-p\right\|^{2}+\tilde{\theta}_{n} .
\end{aligned}
$$


So, $p \in C_{n+1}$. Hence $F \subset C_{n}$ for all $n \in \mathbb{N}$. By the same argument as in the proof of Theorem 3.1, $C_{n}$ is closed and convex, $\left\{x_{n}\right\}$ is well defined. Also, similar to the proof of Theorem 3.1

$$
\lim _{n \rightarrow \infty}\left\|x_{n}-x_{n+1}\right\|=0
$$

We next claim that limsup $\sup _{s \rightarrow \infty} \lim \sup _{n \rightarrow \infty}\left\|T_{i}(s) x_{n}-x_{n}\right\|=0$. Indeed, by definition of $y_{n}$ and $x_{n+1} \in C_{n}$ we have

$$
\begin{aligned}
\left\|y_{n}-x_{n}\right\| & =\left\|\alpha_{n} x_{n}+\left(1-\alpha_{n}\right) \frac{1}{t_{n i}} \int_{0}^{t_{n i}} T_{i}(u) x_{n} d u-x_{n}\right\| \\
& =\left\|\left(1-\alpha_{n}\right) \frac{1}{t_{n i}} \int_{0}^{t_{n i}} T_{i}(u) x_{n} d u-\left(1-\alpha_{n}\right) x_{n}\right\| \\
& =\left(1-\alpha_{n}\right)\left\|\frac{1}{t_{n i}} \int_{0}^{t_{n i}} T_{i}(u) x_{n} d u-x_{n}\right\|
\end{aligned}
$$

and then

$$
\begin{aligned}
\left\|\frac{1}{t_{n i}} \int_{0}^{t_{n i}} T_{i}(u) x_{n} d u-x_{n}\right\| & =\frac{1}{1-\alpha_{n}}\left\|y_{n}-x_{n}\right\| \\
& \leq \frac{1}{1-\alpha_{n}}\left\|y_{n}-x_{n+1}\right\|+\left\|x_{n+1}-x_{n}\right\| .
\end{aligned}
$$

Since $x_{n+1} \in C_{n+1} \subset C_{n}$, we have

$$
\left\|y_{n}-x_{n+1}\right\|^{2} \leq\left\|x_{n}-x_{n+1}\right\|^{2}+\tilde{\theta}_{n}
$$

which in turn implies that

$$
\left\|y_{n}-x_{n+1}\right\| \leq\left\|x_{n}-x_{n+1}\right\|+\sqrt{\tilde{\theta}_{n}}
$$

It follows from (4.5) that

$$
\left\|\frac{1}{t_{n i}} \int_{0}^{t_{n i}} T_{i}(u) x_{n} d u-x_{n}\right\| \leq \frac{1}{1-a}\left(2\left\|x_{n+1}-x_{n}\right\|+\sqrt{\tilde{\theta}_{n}}\right) \longrightarrow 0 \quad \text { as } n \longrightarrow \infty .
$$


Let $L_{\infty}:=\sup \left\{k_{n i}, i=1,2,3, \ldots\right\}$ and for each $i \in\{1,2,3, \ldots\}$, we get that

$$
\begin{aligned}
\left\|T_{i}(s) x_{n}-x_{n}\right\| \leq & \left\|T_{i}(s) x_{n}-T_{i}(s)\left(\frac{1}{t_{n i}} \int_{0}^{t_{n i}} T_{i}(u) x_{n} d u\right)\right\| \\
& +\left\|T_{i}(s)\left(\frac{1}{t_{n i}} \int_{0}^{t_{n i}} T_{i}(u) x_{n} d u\right)-\frac{1}{t_{n i}} \int_{0}^{t_{n i}} T_{i}(u) x_{n} d u\right\| \\
& +\left\|\frac{1}{t_{n i}} \int_{0}^{t_{n i}} T_{i}(u) x_{n} d u-x_{n}\right\| \\
\leq & \left(L_{\infty}+1\right)\left\|\frac{1}{t_{n i}} \int_{0}^{t_{n i}} T_{i}(u) x_{n} d u-x_{n}\right\| \\
& +\left\|T_{i}(s)\left(\frac{1}{t_{n i}} \int_{0}^{t_{n i}} T_{i}(u) x_{n} d u\right)-\frac{1}{t_{n i}} \int_{0}^{t_{n i}} T_{i}(u) x_{n} d u\right\| .
\end{aligned}
$$

By (4.8) and Lemma 2.7, we obtain that

$$
\limsup _{s \rightarrow \infty} \limsup _{n \rightarrow \infty}\left\|T_{i}(s) x_{n}-x_{n}\right\|=0
$$

Furthermore, from (4.9) and Lemma 2.6 and the boundedness of $\left\{x_{n}\right\}$ we obtain that $\emptyset \neq \omega_{w}\left(x_{n}\right) \subset F$. By the fact that $\left\|x_{n}-x_{0}\right\| \leq\left\|p-x_{0}\right\|$ for any $n \geq 0$, where $p=P_{F}\left(x_{0}\right)$ and the weak lower semi-continuity of the norm, we have $\left\|\omega-x_{0}\right\| \leq\left\|p-x_{0}\right\|$ for all $w \in \omega_{w}\left(x_{n}\right)$. However, since $\omega_{w}\left(x_{n}\right) \subset F$, we must have $w=p$ for all $w \in \omega_{w}\left(x_{n}\right)$. Thus $\omega_{w}\left(x_{n}\right)=\{p\}$ and then $x_{n}$ converges weakly to $p$. Moreover, following the method of Theorem 3.1, $x_{n} \rightarrow p=P_{F}\left(x_{0}\right)$. This completes the proof.

Corollary 4.2. Let $C$ be a bounded closed convex subset of a Hilbert space $H$ and $\tau=\{T(t): 0 \leq$ $t<\infty\}$ be an asymptotically nonexpansive semigroup on $C$. Assume also that $0<\alpha_{n} \leq a<1$ for all $n \in \mathbb{N} \cup\{0\}$ and $\left\{t_{n}\right\}$ is a positive real divergent sequence. Then, the sequence $\left\{x_{n}\right\}$ generated by

$$
\begin{gathered}
x_{0}=x \in C, \quad \text { chosen arbitrarily, } \\
y_{n}=\alpha_{n} x_{n}+\left(1-\alpha_{n}\right) \frac{1}{t_{n}} \int_{0}^{t_{n}} T(u) x_{n} d u, \\
C_{n+1}=\left\{v \in C_{n}:\left\|y_{n}-v\right\|^{2} \leq\left\|x_{n}-v\right\|^{2}+\theta_{n}\right\}, \\
x_{n+1}=P_{C_{n+1}}(x), \quad n=0,1,2 \ldots,
\end{gathered}
$$

converges in norm to $P_{F(\tau)} x_{0}$, where $\theta_{n}=\left(1-\alpha_{n}\right)\left[\left(\left(1 / t_{n}\right) \int_{0}^{t_{n}} L_{u} d u\right)^{2}-1\right](\operatorname{diam} C)^{2} \rightarrow 0$ as $n \rightarrow \infty$.

Proof. By Theorem 4.1, if the semigroup $\tau=\{T(t): 0 \leq t<\infty\}=\mathcal{O}:=\{I(t): 0 \leq t<\infty\}$, then $T(t) x_{n}=x_{n}$ for all $n$ and for all $t>0$. Hence $\left(1 / t_{n}\right) \int_{0}^{t_{n}} T(u) x_{n} d u=x_{n}$ for all $n$ and $z_{n}=x_{n}$ then, (4.1) reduces to (4.11). 
Corollary 4.3 (Takahashi et al. [7, Theorem 4.4]). Let $C$ be a nonempty closed convex subset of a Hilbert space $H$ and $\tau=\{T(t): 0 \leq t<\infty\}$ be a nonexpansive semigroup on $C$. Assume that $0<\alpha_{n} \leq a<1$ for all $n \in \mathbb{N} \cup\{0\}$ and $\left\{t_{n}\right\}$ is a positive real divergent sequence. If $F(\tau) \neq \emptyset$, then the sequence $\left\{x_{n}\right\}$ generated by

$$
\begin{gathered}
x_{0} \in C, \quad \text { chosen arbitrarily, } \\
y_{n}=\alpha_{n} x_{n}+\left(1-\alpha_{n}\right) \frac{1}{t_{n}} \int_{0}^{t_{n}} T(u) x_{n} d u, \\
C_{n+1}=\left\{v \in C:\left\|y_{n}-v\right\| \leq\left\|x_{n}-v\right\|\right\}, \\
x_{n+1}=P_{C_{n+1}}\left(x_{0}\right), \quad n=0,1,2 \ldots,
\end{gathered}
$$

converges in norm to $P_{F(\tau)} x_{0}$.

\section{Acknowledgments}

The authors would like to thank professor Somyot Plubtieng for drawing my attention to the subject and for many useful discussions and the referees for helpful suggestions that improved the contents of the paper. This research is supported by the Centre of Excellence in Mathematics, the Commission on Higher Education, Thailand.

\section{References}

[1] W. R. Mann, "Mean value methods in iteration," Proceedings of the American Mathematical Society, vol. 4, pp. 506-510, 1953.

[2] B. Halpern, "Fixed points of nonexpanding maps," Bulletin of the American Mathematical Society, vol. 73, pp. 957-961, 1967.

[3] K. Nakajo and W. Takahashi, "Strong convergence theorems for nonexpansive mappings and nonexpansive semigroups," Journal of Mathematical Analysis and Applications, vol. 279, no. 2, pp. 372379, 2003.

[4] T.-H. Kim and H.-K. Xu, "Strong convergence of modified Mann iterations for asymptotically nonexpansive mappings and semigroups," Nonlinear Analysis: Theory, Methods \& Applications, vol. 64, no. 5, pp. 1140-1152, 2006.

[5] H. Zegeye and N. Shahzad, "Strong convergence theorems for a finite family of asymptotically nonexpansive mappings and semigroups," Nonlinear Analysis: Theory, Methods \& Applications, vol. 69, no. 12, pp. 4496-4503, 2008.

[6] Y. Su and X. Qin, "Strong convergence of monotone hybrid method for fixed point iteration processes," Journal of Systems Science E Complexity, vol. 21, no. 3, pp. 474-482, 2008.

[7] W. Takahashi, Y. Takeuchi, and R. Kubota, "Strong convergence theorems by hybrid methods for families of nonexpansive mappings in Hilbert spaces," Journal of Mathematical Analysis and Applications, vol. 341, no. 1, pp. 276-286, 2008.

[8] Y. Su and X. Qin, "Strong convergence theorems for asymptotically nonexpansive mappings and asymptotically nonexpansive semigroups," Fixed Point Theory and Applications, vol. 2006, Article ID 96215, 11 pages, 2006.

[9] K. Nakajo, K. Shimoji, and W. Takahashi, "Strong convergence to common fixed points of families of nonexpansive mappings in Banach spaces," Journal of Nonlinear and Convex Analysis, vol. 8, no. 1, pp. 11-34, 2007.

[10] Z. Opial, "Weak convergence of the sequence of successive approximations for nonexpansive mappings," Bulletin of the American Mathematical Society, vol. 73, pp. 591-597, 1967.

[11] P.-K. Lin, K.-K. Tan, and H. K. Xu, "Demiclosedness principle and asymptotic behavior for asymptotically nonexpansive mappings," Nonlinear Analysis: Theory, Methods \& Applications, vol. 24, no. 6, pp. 929-946, 1995. 